METALLURGICAL ASPECTS OF FORGE MODELLING IN ALLOY 718

\author{
P.E. MOSSER*, G. LECONTE*, J. LERAY**, A. LASALMONIE*, Y. HONNORAT** \\ Material and Process Laboratory \\ SNECMA - Direction Technique \\ * B.P. 48 - 92234 GENNEVILLIERS CEDEX FRANCE \\ ** B.P. 81 - 91003 EVRY CEDEX FRANCE
}

\begin{abstract}
Alloy 718 is a widely used alloy in SNECMA's engines for applications in forged rotating parts. The most important mechanical property, low cycle fatigue, depends strongly on grain size, which results directly from the forging process. Metallurgical data have been coupled with FORGE2R metal flow numerical results to give a prediction of grain size in recrystallized and dead zones. After calibration, using measurements on forged parts, this approach proved to be an efficient metallurgical forge modelling.
\end{abstract}

\title{
Introduction
}

Alloy 718 is a widely used alloy in SNECMA's engines for applications in forged disks and rotating parts. The major concern with the mechanical properties of these parts is high temperature low cycle fatigue (LCF) resistance, which depends strongly on the grain size (fig. 1). The required fine grained microstructure is obtained during the forging operations. Through the years, parts were submitted to higher stresses and temperatures. This lead to improve matcrial ability through changes of the forging practices. Altogether there was an increasing need at SNECMA forge shop for a forge process modelling which would give, not only a description of metal flow, but also a prediction of the microstructure, and hence of the mechanical properties, in every location of the forged part.

This paper is a presentation of such a model, developped mainly in SNECMA's laboratory. From the metallurgical evolution obtained through thermomechanical testings, microstructure prediction rules are deduced which can be applied to finite element flow modelling results. A real disk forging is confronted with the microstructural prediction.

\section{Metallurgical data}

The microstructure of Alloy 718 may be described by grain size distribution, residual cold work, $\delta$ phase amount and morphology, $\gamma$ " amount and size, carbides, and dendritic segregation. A detailed microstructure description is very difficult and useless for the forge metallurgist. As LCF

Superalloy 718-Metallurgy and Applications

Edited by E.A. Loria

The Minerals, Metals \& Materials Society, 1989 


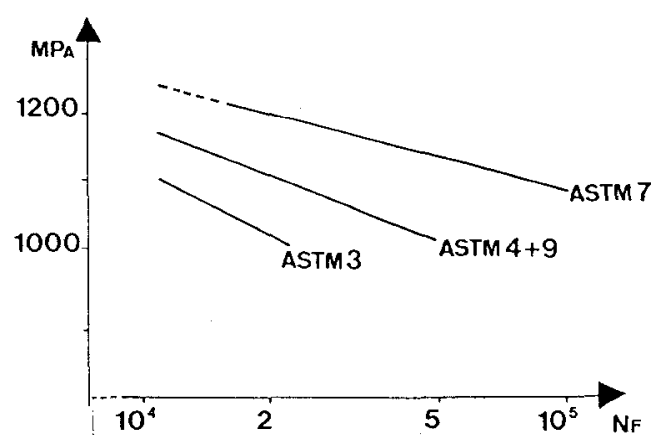

Fig.1: LCF properties vs grainsize

$\mathrm{Nf}$ number of cycles to failure at $550 \mathrm{C}-\mathrm{R}=0$

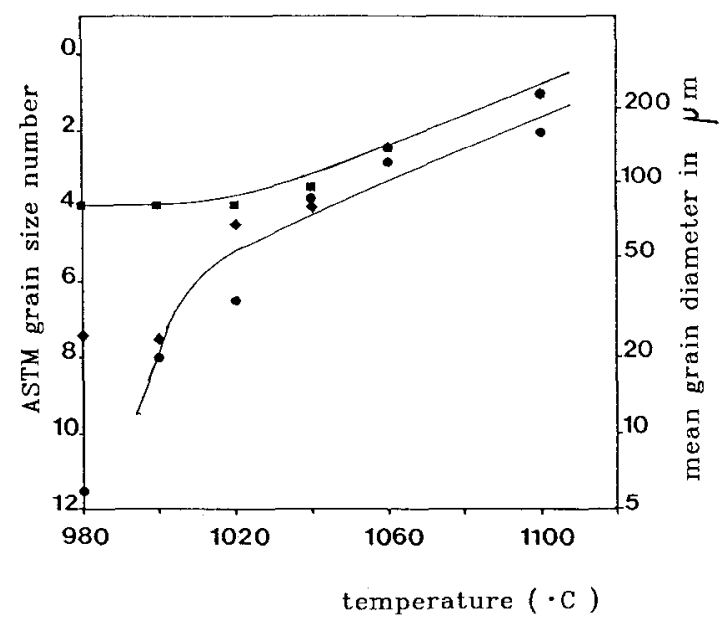

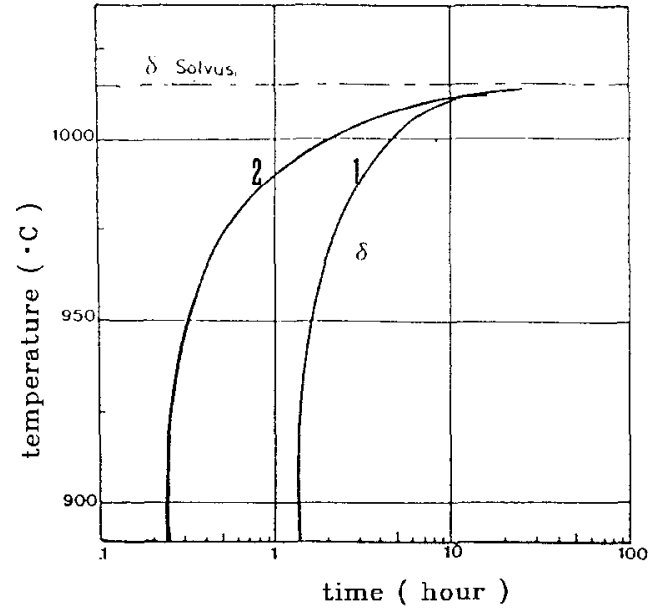

Fig.2: TTT-diagram: precipitation nose 1 ref. 1

2 Snecma's results

Fig.3: Grain-size vs annealing temperature after 1 hour for different initial microstructure.

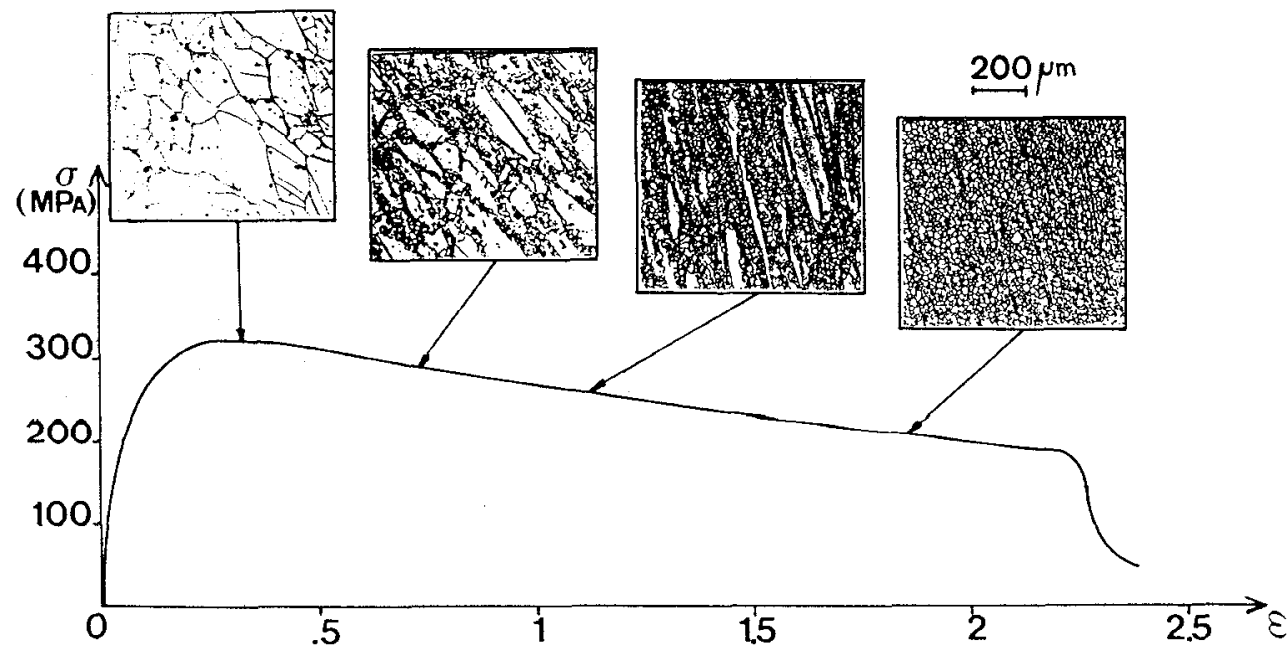

Fig.4: Microstructure and flow stress-evolution during dynamic recrystallization. Conditions of deformation: torsion $/ 1050 \mathrm{c} / 3 . \overline{3 s}$ 
properties depend principally on grain size, we shall focus our attention on grain size prediction, the difficulties being that grain evolution interacts with the evolution of other metallurgical features, such as $\delta$ phase and residual cold work.

\section{Phase diagram}

The phase diagram of Alloy 718 has been first established by Eiselstein [1] and shows the following features :

- above $1010^{\circ} \mathrm{C}$ at equilibrium, the only metallic phase is $\gamma$ - austenite,

- the $\delta$-solvus is determined to be at $1010^{\circ} \mathrm{C}$. However, because of variations in $\mathrm{Nb}$-content due to dentritic segregation, it can vary locally between $990^{\circ} \mathrm{C}$ and $1020^{\circ} \mathrm{C}$. This $\delta$-solvus range is reduced in good quality billets,

- $\delta$ precipitation does not occur very rapidly, except in a structure with a high residual cold-work level,

- $\gamma "$-solvus lies between $900^{\circ} \mathrm{C}$ and $925^{\circ} \mathrm{C}$.

In comparison with these data, SNECMA's own determination of TTT diagram shows a rather important shifting of the precipitation nose towards the shorter times (fig.2).

The forge engineer may draw the following conclusions :

- above $1020^{\circ} \mathrm{C}$ grain growth will occur and will be limited only by carbide precipitation,

- between $970^{\circ} \mathrm{C}$ and $1020^{\circ} \mathrm{C}$, grain growth may be inhibited by $\delta$ precipitates, but around $1000^{\circ} \mathrm{C}$ the resulting microstructure is very sensitive to dendritic segregation,

- cooling down and, more markedly, heating up will induce some $\delta$ precipitation

- normally, forging operations are conducted between $980^{\circ} \mathrm{C}$ and $1120^{\circ} \mathrm{C}$ in the single-phase domain or with a very small amount of $\delta$ phase.

This last remark is an additional justification for SNECMA's choice to model first the grain size evolutions, neglecting somehow the influences of $\delta$ phase and residual cold work.

\section{Static recrystallization}

Static recrystallization occurs mainly during the preheating and heating sequence before forging and also before quenching. The $\delta$-solvus temperature separates two domains in the kinetics of grain growth (fig 3 ).

Above the $\delta$-solvus $\left(1020^{\circ} \mathrm{C}\right.$ to take segregation into account) a near-equilibrium grain size is reached after an one-hour-annealing. Grain growth between 1 hour and 4 hours anneal is very limited and would lead to the same ASTM quotation due to the scatter of the conventional measuring method. This equilibrium grain size is independent of the initial microstructural state and depends only of the annealing temperature following the experimental correlation :

or

$$
\mathrm{d}=75 \mathrm{x} \exp [0.015(\mathrm{~T}-1020)] \text { with } \mathrm{d} \text { in } \mu \mathrm{m} \text { and } \mathrm{T} \text { in }{ }^{\circ} \mathrm{C}
$$

$$
\text { GS }=4+0.015(T-1070) \quad \text { with GS in ASTM }
$$

This formula is valid between $1020^{\circ} \mathrm{C}$ and $1100^{\circ} \mathrm{C}$, and provided that initial grain size is finer than $75 \mathrm{\mu m}$. Its imprecision is $\mp 1$ ASTM.

For shorter annealing time, it appears that a similar formula can be applied. But in this casc the grain size would depend on the initial microstructure. 
Below $980^{\circ} \mathrm{C}$, for annealing durations representative of preheating sequences, the grain size does not vary at all. In between, grain size evolution would depend strongly on the initial microstructurc, $\delta$ precipitate content and residual cold work. In particular, a strong dendritic segregation can lead to alternate bands with grain size variations up to 4 ASTM.

\section{Dynamic recrystallization}

When Alloy 718 is deformed above $950^{\circ} \mathrm{C}$ and at rates higher than $10^{-4}$ $\mathrm{s}^{-1}$, the first grain refinement mechanism is dynamic recrystallization. An exemple of microstructural evolution is given on fig.4. Dynamic recrystallization starts at a critical strain $\varepsilon_{c r}$, just below the maximum flow stress value. Small refined grains appear at the prior grain boundaries. The recrystallized fraction increases with deformation, forming necklace and duplex microstructures. A steady-state fully recrystallized structure is reached at $\varepsilon_{S}$ with an homogeneous grain size $d_{3}$. Modelling the microstructure after forging involves predicting the grain size of both the cold worked and the recrystallized grains as well as the recrystallized volume f'raction.

Recrystallization threshold $\varepsilon_{c r}$. The value of the critical strain classically increases with strain rate $\varepsilon$ and decreases with temperature. However a good correlation exists between the peak stress and the recrystallization threshold (fig. 5). For strain rate values representative of those for isothermal forging $\left(10^{-3} \mathrm{~s}^{-1}<\dot{\varepsilon}<10^{-2} \mathrm{~s}^{-1}\right), \quad \varepsilon$ or may be estimated to be smaller than 0.15. For conventional press forging $\left(\dot{\varepsilon}=10^{-1}\right.$ $\left.\mathrm{s}^{-1}\right), \varepsilon_{\mathrm{cr}}$ is around 0.2 . No experimental results are available for strain rate values applicable to hammer forging $\left(10 \mathrm{~s}^{-1}<\dot{\varepsilon}<100 \mathrm{~s}^{-1}\right)$; however fig. 6 shows that for $\dot{\varepsilon}=6 \mathrm{~s}^{-1}$, $\varepsilon_{\text {or }}$ is higher than 0.4 ; it is 1 ikely that, usually, $\varepsilon_{c r}$ is so large that dynamic recrystallization is negligeable and only metadynamic recrystallization is to be considered. In all the cases $\varepsilon_{\text {or }}$ decreases very slowly with temperature (fig. 6).

Steady state grain size $d_{S}$. It is often found that $d_{S}$ is a function of the Zener-Hollomon parameter

$$
\mathrm{d}_{\mathrm{S}}{ }^{-1}=\mathrm{k} \log \mathrm{Z} \quad \mathrm{Z}=\dot{\varepsilon} \exp \mathrm{Q} / \mathrm{RT}
$$

where $Q$ is the self diffusion energy [2]. So that $d_{S}$ is expected to decrease with $\varepsilon$ and increase with $T$. In Alloy 718 , lhe results are conflicting since, for instance, camus et al. [3] found that $d_{s}$ increases with $\dot{\varepsilon}$ in the range $4 \times 10^{-2} \mathrm{~s}^{-1}$ to $4 \mathrm{~s}^{-1}$, whereas we found no real dependance of $d_{s}$ between $10^{-1} s^{-1}$ and $6 s^{-1}$ (table 1 ).

\begin{tabular}{|l|l|l|l|}
\hline strain-rate $\left(\mathrm{s}^{-1}\right)$ & .09 & 3.3 & 6.0. \\
\hline grain size (ASTM $)$ & 9.5 & 9.0 & 9.5 \\
\hline
\end{tabular}

Table 1: Evolution of grain size with strain-rate at $1050 \mathrm{C}$

Two reasons may explain this discrepancy. In most rheological torsion testings, the quench is reported to happen 1 or 2 seconds after the end of the deformation; this time is longer than the deformation time when the strain rate is high $\left(e . g \cdot \dot{\varepsilon}>1 \mathrm{~s}^{-1}\right)$; so that one can suppose, and Camus [3] mentions some metallographical evidence of it, that at these fastest strain rates metadynamic recrystallization must occur before quenching. The sccond reason is that over $\dot{\varepsilon}=0.1 \mathrm{~s}^{-1}$, the deformation is almost adiabatic and that after a deformation $\varepsilon=1$ the temperature rise can be as 


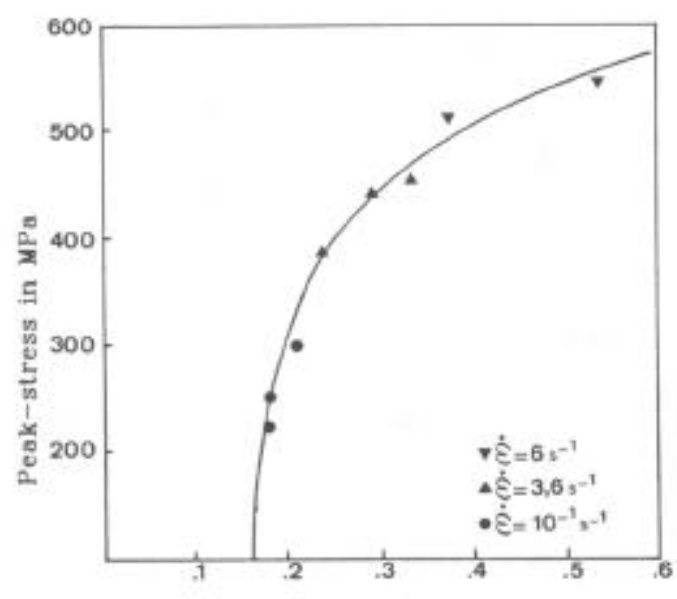

Fig.5: Peak-stress vs threshold-strain

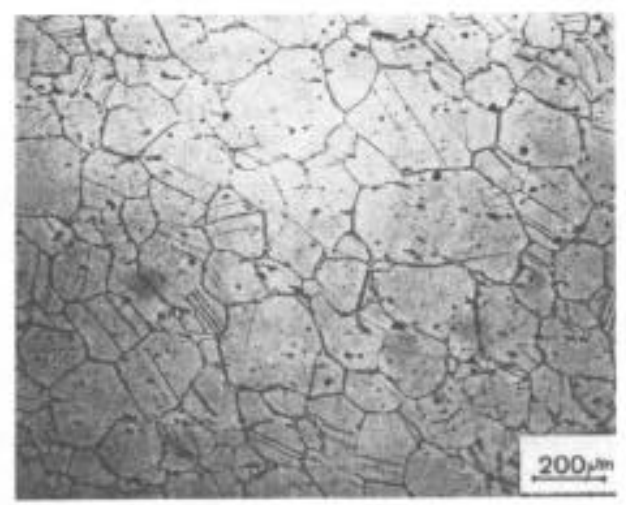

Fater-quenched

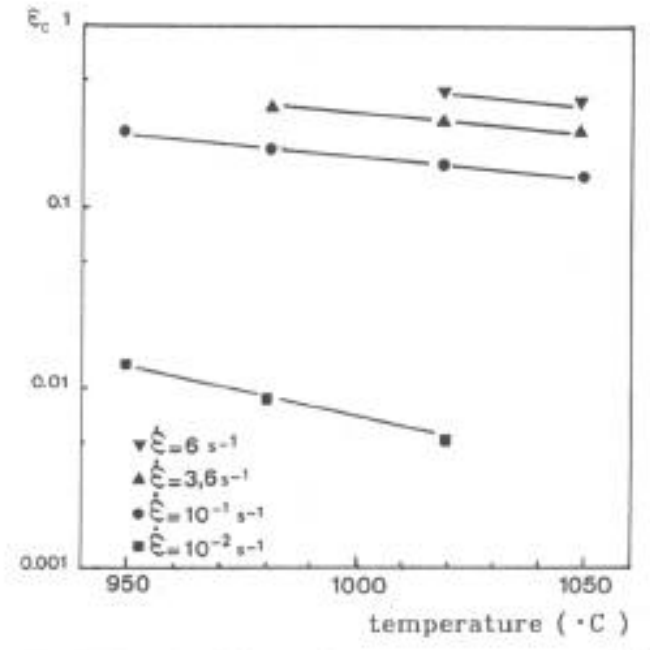

Fig.6: Threshold strain va temperature and strain-rate.

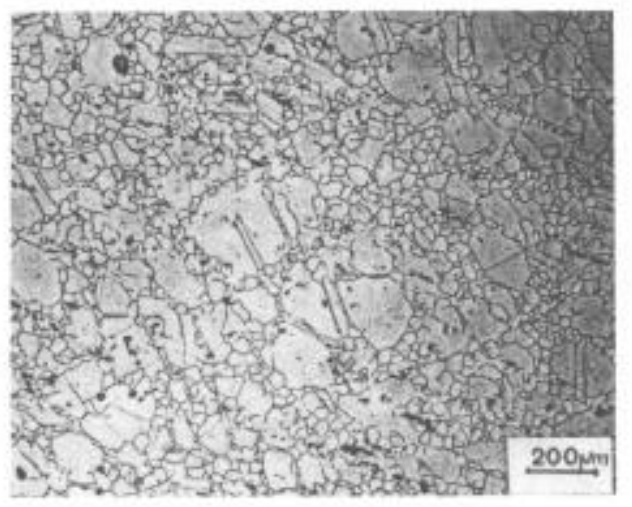

Air-cooled

Fig.7: Influence of the cooling-down rate on the recrystallized fraction.

Conditions of deformation: $1050 \mathrm{c} / 3 . \overline{3} \mathrm{~s} / 0.14$
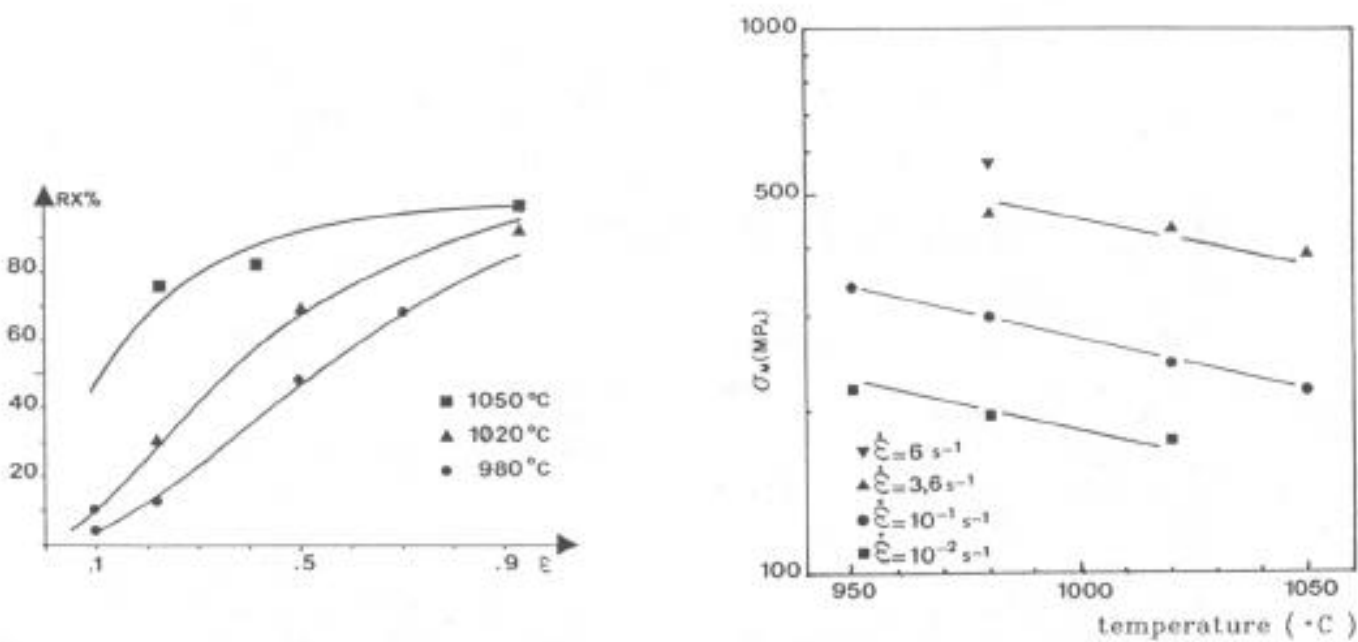

Fig.8: Metadynamic recrystallization. Evolution of recrystallized fraction with temperature and strain

Fig.9: Peak-stress vs temperature and strain rate 
high as $75^{\circ} \mathrm{C}$. We can assume that relation (1) would be verified for quenching occuring very soon after the deformation ends and if one took into account the instantaneous temperature.

In the actual case where the cooling rate is slow, we found that the main parameter influencing $d_{S}$ was the initial deformation temperature $T$. The experimental relationship between $d_{S}$ and $T$ when both dynamic and metadynamic recristallization are active, is given on table 2 .

Steady state deformation $\varepsilon_{S}$. The determination of $\varepsilon_{S}$, suffers from the same difficulty than that of $d_{S}$ : one has to compensate for adiabatic heating. Even in that case, the values reported in the litterature are so high, over 1,2 - 1,5, that they are reached very seldom during one forging operation. Dynamic recrystallization is to be continued by metadynamic recrystallization.

\section{Motadynamic recrystallization}

Metadynamic recrystallization is a static recrystallization process occuring just after the end of deformation; but it is quicker since there is no intermediate cooling down and heating up leading to $\delta$ phase precipitation. Dynamic recrystallization results (see section above) show that in most cases, metadynamic recrystallization must occur to achieve a fully recrystallized state at the end of a forging. Fig 7 shows the difference in microstructural state after deformation, for two different cooling rate. In the slowly cooled specimens new grains have nucleated and grown at the expense of cold worked ones, leading to a necklace structure, whereas in the water-quenched specimens, these new recrystallized grains are to be seen only from place to place. For slowly cooled specimens, the recrystallized fraction depends on both initial deformation temperature and initial microstructure. Fig 8 shows this evolution for an initial microstructure of 3 ASTM. The recrystallized grain size is of the same order or a little finer than after dynamic recrystallization at the same temperature (table 2).

\begin{tabular}{|c|c|c|}
\hline & \multicolumn{2}{|c|}{ grain size after ..... ( ASTM ) } \\
\hline temperature $(\cdot \mathrm{C})$ & $\begin{array}{l}\text { dynamic recrys- } \\
\text { tallization }\end{array}$ & $\begin{array}{l}\text { metadynamic } \\
\text { recrystallization }\end{array}$ \\
\hline 1050 & 7 & 8.5 \\
\hline 1020 & 8 & 10 \\
\hline 980 & 9.5 & 11 \\
\hline
\end{tabular}

Table 2: Evolution of grain size with recrystallization temperature.

Conditions of deformation:

dynamic recryst. $\quad: 3.3^{-1} \mathrm{~s} /$ air quench metadynamic recryst. : . $1 \mathrm{~s}^{-1} / \mathrm{air}$ cool

Metallurgical data base for Alloy 718

There are some difficulties in establishing an exhaustive metallurgical data base for forging purposes. Part of them arise from the measuring techniques of the microstructural parameters. For instance, no technique gives in reasonable time unquestionnable values for $\delta$ content and precipitate size for an exhaustive set of thermal and deformation conditions for the moment. Following this lack of reliable measurements, it becomes almost impossible to identify an existing precipitation or solutioning model. Other difficulties come from the rheological experiments. On one hand, one has to cope with very strong coupling between strain and temperature, so that at medium and high strain rates an isothermal experiment is unrealistic; on the other hand, a correct freezing of the microstructure must be achieved in a shorter time than the deformation process itself. Generally this appears not to be the case. 
As a consequence of these difficulties the metallurgical results are not reliable enough to feed physically established relationships between structural state variables and process variables but can give the general trends and some approached values describing the metallurgical structure resulting from the process.

\section{Metallurgical modelling of disk hammer forging}

The aim of this modelling is to provide a grain size prediction. The method consists in deriving the expected microstructure from the calculated strain distribution within the part, using an isothermal flow modelling. It has been initiated using rules which will be exposed further, then calibrated, comparing cxporimontal rosults with the calculatcd microstructure.

As it does not take into account temperature and time effects, it is not a general model and is to be applied only for the process which it has been calibrated with. It is of no use for comparing two different processes as will be shown further. But it allows to compare different geometrical solutions for the forging of a part in a single tightly controlled process.

\section{Metal flow model}

At SNECMA's we use the finite element program FORGE2R, developped in cooperation with the CEMEF (Ecole des Mines), which has already been extensively described elsewhere [4]. The main hypothesis for the calculations are : no gravity nor inertial forces, incompressibility and isotropy of the material, NORTON-HOFF viscoplastic behaviour $\left(\sigma_{0}=\mathrm{K}^{\mathrm{m}}\right)$, fluid boundary layer friction law $(\tau=\alpha \Delta V P)$, rigid dies.

Originally the program had an isothermal formulation. Now the thermal coupling has been incorporated. But the results presented here are only isothermal.

The flow rule for Alloy 718 is given on fig.9. We choose to represent only the peak stress as a function of strain rate only, including neither strain hardening nor softening. Strain hardening would result in a more uniform deformation within the part, so that calculations give rather conservative values. On the contrary, an eventual flow softening would increase strain localization, making the model inadequate. But, as we never experienced such a trend for Alloy 718 in the hot working range, the peak-stress approximation is considered to be coherent with the isothermal formulation.

The friction factors are chosen so as to be equivalent to a Tresca coefficient of $\mathrm{m}=.3[5]$.

As we don't consider the time-dependance of temperature nor the one of metallurgical structure, we consider the hammer-ram velocity as constant.

\section{Initial metallurgical data for grain size prevision}

These rules derive from the results shown previously :

- grain size after preheating and heating is given in fig.3,

- depending on the deformation temperature and the strain level, the microstructural aspect will be unrecrystallized, duplex or fully recrystallized (fig.8), 


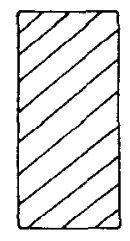

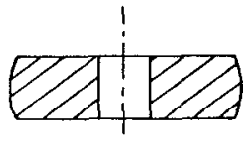

Upsetting + piercing

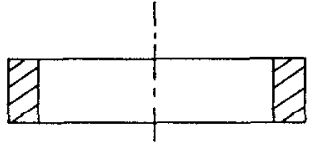

Ring-rolling

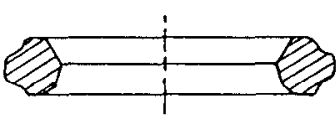

Finish hammer forging

Fig.10: General forging sequence of a CFM56-L.PT-disk

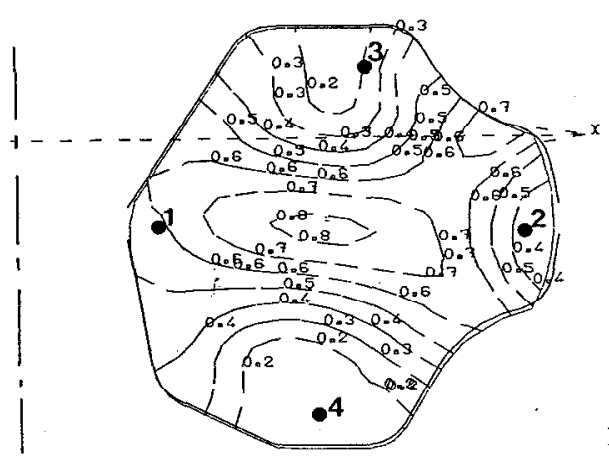

Fig.11: Final strain distribution in LPT-disk forging.

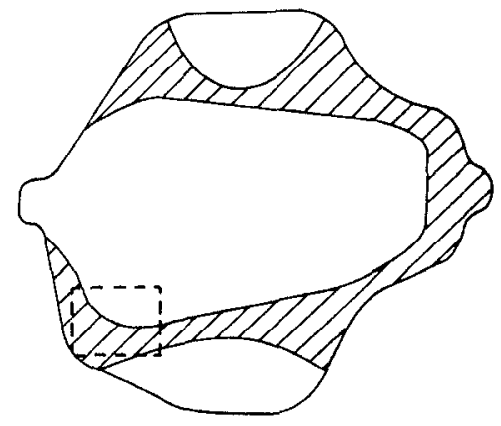

Dead zone(DZ)

\begin{tabular}{|l|l|l|l|}
\cline { 2 - 4 } \multicolumn{1}{l|}{} & \multicolumn{2}{c|}{$\begin{array}{c}\text { Grain size } \\
\text { ASTM }\end{array}$} \\
\hline \multirow{2}{*}{$\begin{array}{l}\text { forging tem } \\
\text { perature }\end{array}$} & $\mathrm{RX}$ & $\mathrm{DZ}$ \\
\cline { 2 - 4 } Duplex zone & $1100 \mathrm{C}$ & 6 & 2 \\
$1060 \mathrm{C}$ & 7.5 & 4 \\
$1020 \mathrm{C}$ & 10 & 6 \\
\hline
\end{tabular}

Fig.12: Mean Inicrostructure distribution in a LPT -disk forging
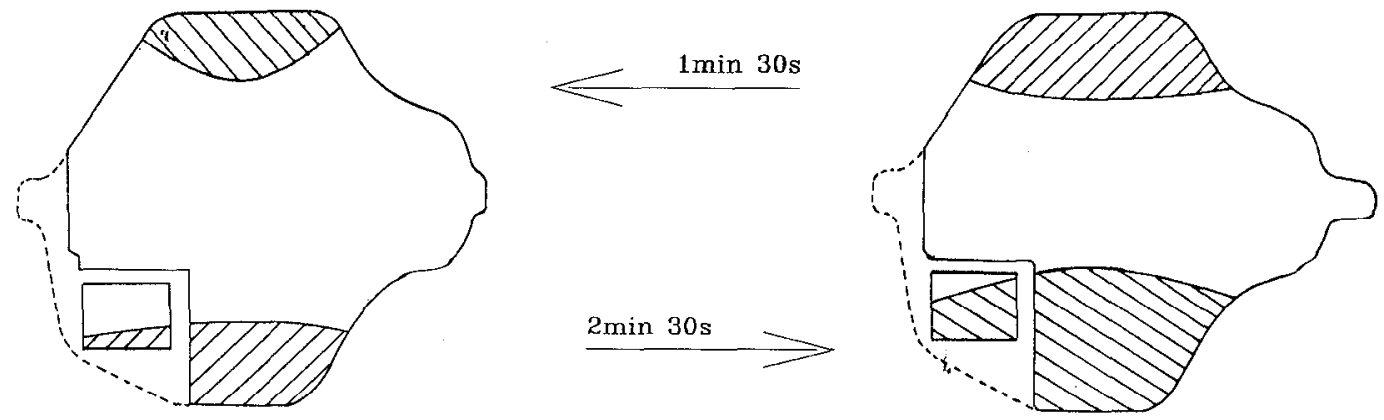

Fig.13: Dead-zone limits in relation with final forging duration. 
- the main grain refinement mechanism is metadynamic recrystallization ; so that recrystallized volumic fraction will also depend on the cooling rate,

- the size of unrecrystallized grains in the dead zones remains unaffected during the forging,

- the size of recrystallized grains is given on table 1.

Turbine disk forging

Through the years, the CFM-56 engine has been improved in terms of efficiency and thrust leading to an increasing of the disks temperatures and stresses. During this period the forging temperature has been reduced to improve material capabilities. This section will show an example of forge modelling in order to control the microstructure in an Alloy $718-10$ w pressure turbine (LPT) disk.

The general forging sequence consists in an upset + piercing stage, a ring-rolling operation and a finishing hammer forging (fig 10). Up to now we conduct all the forging operations above $\delta$-solvus, so that we consider that the final microstructure results mainly from the 1 ast operation. We have inus modelled only the finishing hammer forging. Mechanical specifications are particularly severe at the rim, the bore and at both flanges.

\section{Numerical modelling}

The engineering strain at the end of the forging operation is represerlied in fig.11. In most of the volume, especially at the bore and at the rim, the strain level is higher than 0.3, resulting through dynamic and metadynamic recrystallization in an almost fully recrystallized structure. However, two dead zones appear in the flanges, characterized by strain levels below 0.3 .

\section{Disk forging}

Micrographs of forged disk sections show a good correlation between the calculated strain distribution and the type of microstructure: cold-worked, duplex or recrystallized at any tested temperature, but the recrystallized grain size in the real forging is finer than predicted by the rheological testing (fig. 12). This fact leads to the expected need for a calibration. It can be attributed to limited knowledge of the local temperature. Another local temperature effect is frequently observed at the surface of the forging, where a duplex structure appears, despite a high strain level ( $\mathrm{fig} .10$ and 11 : location A).

The prediction of the dead zone locations can be altered by a change in the process as shown on fig.13. The time between two blows has been increased in the second process so that the forging operation lasts 2 min $30 \mathrm{~s}$ instead of $1 \mathrm{~min} 30 \mathrm{~s}$, resulting in a final skin tomperature below $900^{\circ} \mathrm{C}$. The temperature at the end of the forging has thus become insufficient to recrystallize metadynamically and the dead zones have increased.

\section{Conclusion}

Metallurgical experimentations have been performed to study elementary mechanisms of grain growth and refinement. Above $\delta$-solvus, despite conflicting results, one can derive qualitative rules to predict grain size evolution in static, dynamic and metadynamic evolution. 
Using an isothermal metal flow modelling and the metallurgical rules one can obtain a useful grain size prediction. In particular, dead zone locations may be deduced. However in order to give the recrystallized grain size, the model has to be calibrated with real forgings.

SNECMA has integrated this modeling in its forging practice in order to analyze its present production and the design of new forgings.

[1] H.L. EISELSTEIN " Metallurgy of a Columbium - Hardened Nickel-Chromium-Iron Alloy " Advances in the Technology of Stainless Steels and Related Alloys, ASTM-STP 369 (1965), 62-79

[2] M. UEKI, S. HORIE, T. NAKAMURA "Factors Affecting Dynamic Recrystallization of Metals and Alloys ", Materials Science and Technology, May 1987, vol. 3, 329-337.

[3] Gerald CAMUS, Bernard PIERAGGI, and Francois CHEVET "Hot Deformation and Recrystallization of Inconel 718 ", Symposium proceedings : formability and Metallurgical structures, October 86, Orlando, PMS 87, ed. A.K. GACHDEV, J.D. EMBURY, p. $305-326$

[4] Yves GERMAIN, Pierre-Etienne MOSSER, "Finite element analysis of shaped lead-tin disk forgings" NUMIFORM 86, A.A. BALKEMA, ROTTERDAM, BOSTON

[5] Pierre-Etienne MOSSER, Yves GERMAIN, "Le modèle de forgeage isotherme FORGE2", 65th SMP AGARD - CP 426, CESME 2-4 OCTOBER 1987 